\title{
Congruence between strain morphology and the 165 rRNA gene sequence
}

The application of PCR and technical improvements that have made DNA sequencing rapid and inexpensive have also boosted interest in microbial taxonomy. Nowadays, phylogenetic placement of microbial isolates may be inferred with ease and rapidity. However, the sensitivity of PCR might lead to erroneous conclusions. In our experience, direct PCR amplification from a plate may lead to the amplification of the $16 \mathrm{~S}$ rRNA genes from strains that were not directly visible on the original plate. As an example, Conexibacter woesei was discovered fortuitously by direct PCR from a culture plate on which a different bacterium was growing. The discrepancy between the morphology of the strain visible on the plate and the phylogenetic 
assignment of the PCR-amplified 16S rRNA gene sequence eventually led to the identification of $C$. woesei in pure culture (Monciardini et al., 2003).

Due to our interest in actinomycetes that produce novel biologically active substances, our attention was drawn to an article by Ezra et al. (2004) that appeared in the April issue of Microbiology. The authors reported the recovery of an endophytic verticillate Streptomyces species that produced coronamycins, novel biologically active peptides. This finding appears to be of extreme interest and opens new perspectives in natural product discovery. However, we believe that the producer strain might have been misclassified. Their article prompted us to compose this general comment.

Classification of strain MSU-2110 as a Streptomyces species was based on morphological and molecular data. The strain was originally believed to be an endophytic fungus, but spore size suggested it could be an actinomycete. In fact, scanning electron micrographs of strain MSU-2110 shown in Fig. 2 of the original article (Ezra et al., 2004) do not support this assertion for different reasons: the dimension of spores $(2 \cdot 7-2 \cdot 8 \times 1 \cdot 5-1 \cdot 6 \mu \mathrm{m})$ is too big for streptomycetes, whose spores usually do not exceed $0 \cdot 5-1 \times 1 \cdot 3-1.5 \mu \mathrm{m}$; the lemon-like spore shape is unknown for streptomycetes, which have doliform to rod-like spores; the shape of conidiophores is different from that of actinomycetes such as Streptoverticillium where the branching whorls have the same diameter as the hyphae and do not present enlargements followed by restrictions as those shown in Fig. 2(c) (Williams et al., 1989; Miyadoh et al., 2002). The authors themselves recognize this as an uncommon morphology, and use 16S rRNA gene sequence analysis to confirm the morphological attribution to the verticillate group of streptomycetes.

However, the data presented further contrast with the affiliation of strain MSU-2110 to the genus Streptomyces. The partial 16S rRNA gene sequence that Ezra et al. (2004) obtained, in fact, is only distantly related to those of members of this genus. The reported $94 \%$ identity with Streptomyces caelestis is quite low, and it is limited to a relatively short portion of the gene. When the entire $912 \mathrm{nt}$ sequence is aligned with the $16 \mathrm{~S}$ rRNA gene sequence of $S$. caelestis NRRL $2418^{\mathrm{T}}$, the overall identity is below $90 \%$. In contrast, a search in GenBank reveals high identity $(99 \cdot 2 \%)$ to the $16 \mathrm{~S}$ rRNA gene sequence of Kocuria kristinae DSM $20032^{\mathrm{T}}$ and to other strains of the genera Kocuria, Rothia, Nesterenkonia, Micrococcus and Arthrobacter. Sequence data therefore suggest that the PCR-amplified 16S rRNA gene does not derive from a Streptomyces species, but from a strain whose morphology is not consistent with the description of strain MSU-2110. Kocuria and related genera, in fact, do not form a complex mycelium, but have simple coccoid cells of about $1-1.5 \mu \mathrm{m}$ in diameter (Stackebrandt et al., 1995).

Ezra et al. (2004) amplified the 16S rRNA gene directly from a culture growing on an agar plate, using PCR primers specific for Bacteria. As noted earlier, the extreme sensitivity of PCR might give rise to misleading conclusions. Moreover, the primer set used is biased towards amplification of bacterial rRNA genes. The use of 'Universal' PCR primers, which can amplify also the small-subunit (SSU) rRNA genes from eukaryotes, might have revealed a different picture.

In our opinion, the data provided by Ezra et al. (2004) fail to substantiate their claim that strain MSU-2110 is the first verticillate endophytic streptomycete described in the literature. In this particular case, further analyses should be performed for classification of the coronamycin-producing strain. More generally, when uncommon morphologies are associated to a SSU sequence highly related to those of known microbes, or when divergent sequences are obtained from a novel microbial isolate, it is important to rule out possible PCR-related biases (including preferential amplification of a minor representative in the culture) before actually claiming strain novelty.

\section{Linda Cavaletti and Paolo Monciardini}

Vicuron Pharmaceuticals Italy s.r.l., via R. Lepetit 34, 21040 Gerenzano (VA), Italy

Correspondence: Paolo Monciardini (pmonciardini@vicuron.it)
Ezra, D., Castillo, U. F., Strobel, G. A. \& 10 other authors (2004). Coronamycins, peptide antibiotics produced by a verticillate Streptomyces sp. (MSU-2110) endophytic on Monstera sp. Microbiology 150, 785-793.

Miyadoh, S., Tsuchizaki, N., Ishikawa, J. \& Hotta, K. (editors) (2002). Digital Atlas of Actinomycetes (http://www.nih.go.jp/saj/ DigitalAtlas). Tokyo: The Society for Actinomycetes Japan.

Monciardini, P., Cavaletti, L., Schumann, P., Rohde, M. \& Donadio, S. (2003). Conexibacter woesei gen. nov., sp. nov., a novel representative of a deep evolutionary line of descent within the class Actinobacteria. Int J Syst Evol Microbiol 53, 569-576.

Stackebrandt, E., Koch, C., Gvozdiak, O. \& Schumann, P. (1995). Taxonomic dissection of the genus Micrococcus: Kocuria gen. nov., Nesterenkonia gen. nov., Kytococcus gen. nov., Dermacoccus gen. nov., and Micrococcus Cohn 1872 gen. emend. Int J Syst Bacteriol 45, 682-692.

Williams, S. T., Goodfellow, M. \& Grace, A. (1989). Genus Streptomyces Waksman and Henrici 1943, 339 ${ }^{A L}$. In Bergey's Manual of Systematic Bacteriology, vol. 4, pp. 2452-2492. Edited by S. T. Williams, M. E. Sharpe \& J. G. Holt. Baltimore: Williams \& Wilkins.

DOI 10.1099/mic.0.27455-0 